\title{
Nuclear alterations in hepatocytes of Arctic char Salvelinus alpinus from acidic high alpine lakes
}

\author{
Rudolf Hofer ${ }^{1}$, Günter Köck ${ }^{1}$, Thomas Braunbeck ${ }^{2, *}$ \\ ${ }^{1}$ Institute of Zoology and Limnology, University of Innsbruck, Technikerstr. 25, A-6020 Innsbruck, Austria \\ ${ }^{2}$ Department of Zoology I, University of Heidelberg, Im Neuenheimer Feld 230, D-69120 Heidelberg, Germany
}

\begin{abstract}
The hepatocyte morphology of Arctic char Salvelinus alpinus from 2 acidic, a circumneutral and 3 alkaline lakes in the Austrian Alps (Tyrol and Styria) was compared with respect to nuclear alterations and related to environmental parameters. Extensive glycogen storage of hepatocyte nuclei could regularly be found in Arctic char from the 2 acidic high mountain lakes. In contrast, in Arctic char from the circumneutral lake (slightly acidic during winter), nuclear glycogen storage could only be documented in a few specimens. In alkaline lakes, however, nuclear glycogen deposition was absent in 64 out of 65 specimens. Additional nuclear pathology in char of the most acidic lake was evident from a reorganization of nucleolar components. The number of nuclei involved in glycogen storage showed a distinct seasonal pattern which correlated with the intensity of feeding, but not with the seasonality of other environmental parameters (trace metals, temperature, $\mathrm{pH}$ ).
\end{abstract}

KEY WORDS: High mountain lakes Acidification Arctic char - Liver pathology - Ultrastructure Nucleus - Glycogen

\section{INTRODUCTION}

During the last few decades, fish populations of thousands of low alkalinity lakes in the northern United States, in eastern Canada and in Scandinavia have decreased or have been completely eradicated due to progressively increasing levels of acidity (Harvey et al. 1981. Hendriksen et al. 1989, Bulger et al. 1993). Industrial emissions of sulphuric and nitric acids have had an impact even on remote lakes, which may be unable to buffer the acid precipitation due to their geological background (Mason 1989). During this century, $\mathrm{pH}$ and alkalinity of sensitive lakes have decreased by approximately 0.8 units and $28 \mu_{\text {eq }} \mathrm{l}^{-1}$, respectively (Psenner 1994). However, acidification does not simply mean a decrease of $\mathrm{pH}$, but frequently also includes progressive mobilization of metals (Hutchinson et al. 1987, Hutchinson \& Sprague 1989, Reader \& Dempsey 1989, Köck et al. 1995), particularly of aluminum (Backes \& Tipping 1987), which has repeatedly

- Addressee for correspondence.

E-mail: braunbeck@urz.uni-heidelberg.de been shown to be extremely harmful to fish (Baker \& Chofield 1982).

Acute effects of acidification on fish can be seen in running waters in which acid precipitation or acid runoff during snow melt leaches aluminum from the watershed. These episodic events result in severe damage to gills (Daye \& Garside 1975, McDonald 1983, Chevalier et al. 1985, Mason 1989) or even fish kills (McDonald \& Wood 1993). In lakes of low alkalinity, however, fish are chronically exposed to sublethal concentrations of acids and metals. At least adult fish have been shown to be capable of acclimatization to such extreme environmental conditions (McDonald \& Wood 1993); their reproductive success, however, may be gradually impaired. Reduced egg production or declining spawning rates (Beamish et al. 1975, McCormick et al. 1989), decreased hatching rates of larvae (Daye \& Garside 1979) and particularly increased lethality to swim-up fry as the most sensitive developmental stage (Sayer et al. 1993) are common effects of progressive atmospheric pollution on fish populations in acidic lakes.

Sublethal effects of acids and aluminum have primarily been studied with respect to gill structure and 
function (Leino \& McCormick 1984, Karlsson-Norrgren et a1. $1986 \mathrm{a}, \mathrm{b}$, Leino et al. $1987 \mathrm{a}, \mathrm{b}$ ). Thus, increased mucus secretion (Fischer-Scherl \& Hoffmann 1988) as well as hyperplasia, hypertrophy and necrosis of gill epithelia (Chevalier et al. 1985) have been described in addition to respiratory, haematological and ionoregulatory responses (Fromm 1980, McDonald 1983, Wood 1989). In contrast, little information is available about the influence of acidic environments on the morphology and physiology of other organs such as the liver, kidney, skin or pituitary gland of fish (Wendelaar-Bonga et al. 1986, Segner \& Pechlaner 1987, Segner et al. 1987). Since the liver has repeatedly been demonstrated to react to numerous internal and external stimuli including sexual activity (Peute et al. 1985), season (Segner \& Braunbeck 1990), temperature (Braunbeck et al. 1987), starvation and malnutrition (Segner \& Braunbeck 1988), as well as various xenobiotics (Braunbeck 1994), the present study was designed to compare the histo- and cytopathology of hepatocellular nuclei in declining populations of Arctic char from 2 acidic high mountain lakes with those from well-reproducing populations from circumneutral or alkaline lakes.

\section{MATERIAL AND METHODS}

Sampling sites and dates. Arctic char of 6 oligotrophic alpine lakes in Austria (Table 1) were caught with gill nets or rod and line during summer and winter, respectively. Gill nets were checked every 30 to 40 min. Samples were taken from: Schwarzsee (SOS), Drachensee (DRS), Mittlerer Plenderlesee (MPL), and Oberer Plenderlesee (OPL), which are high mountain lakes located in the Ötztal Alps (Tyrol), from Achensee (ACH) near Jenbach (Inn valley, Tyrol) as well as from Grundlsee (GRS; Totes Gebirge, Styria). In DRS, ACH and GRS only 1 sample was taken (October); in MPL 2 samples (July and September), in SOS 6 (April to September) and in OPL 5 samples (March to September) were taken. During transport to the laboratory (1.5 to $2 \mathrm{~h}$ ), water was aerated and maintaimed at the same temperature as the sampled lake. Fish from all sampling sites were treated in the same way.

Water analysis. Chemical and physical parameters of the water are listed in Table 1. For more detailed information on water characteristics of the lakes, see Köck et al. (1995). Measurements of $\mathrm{pH}$ in waters of low ionic strength raise methodical problems (Hoenicke et al. 1991) due to low conductivity, low buffering capacity and imbalanced $\mathrm{CO}_{2}$ contents of the water. In fact, data taken immediately after sampling slightly differed from those obtained after transfer to the laboratory. For the present study, an Ingold $\mathrm{pH}$ electrode recommended for $\mathrm{pH}$-measurements in low ionic strength water was equilibrated at the temperature conditions of the lake. The $\mathrm{pH}$ of the water was measured in the field immediately after sampling. In situ temperature of the lakes was measured with a temperature electrode.

For cadmium analysis, water samples of SOS were filtered in the field through $0.45 \mu \mathrm{m}$ cellulose acetate membranes and acidified for preservation. Analyses were performed with a Hitachi Z-8200 graphite furnace atomic absorption spectrophotometry (GFAAS) with Zeeman background correction. Due to low cadmium concentrations, the 'sample concentration' option was used. Cadmium concentrations are given as volume-weighted means

Morphometry. Fish were killed by a blow on the head. Weights of body, liver and stomach contents as well as total length were measured and opercula bones as well as otoliths were dissected for age determination.

Light microscopy. For light microscopical studies, pieces of liver were fixed in $5 \%$ formaldehyde ( $\mathrm{pH} 7.4$ ), dehydrated in a graded series of ethanol and embed-

Table 1 Physical and chemical parameters of the lakes investigated. Data from Köck et aI. (1995). SOS: Schwarzsee; MPL: Mittlerer Plenderlesee; OPL: Obercr Plenderlesee; DRS: Drachensee; ACH: Achensee; GRS: Grundlsee. Data for depth of water samples from SOS, MPL, OPL, and DRS represent volume-weighted means (see Köck et al. 1995); for ACH and GRS, means at 30 to $50 \mathrm{~m}$ depth during autumn (specific environment of Arctic char in these lakes) are given

\begin{tabular}{|c|c|c|c|c|c|c|}
\hline & SOS & MPL & OPL & DRS & $\mathrm{ACH}$ & GRS \\
\hline Altitude $(\mathrm{m})$ & 2799 & 2317 & 2344 & 1874 & 929 & 712 \\
\hline Conductivity $\left(\mu \mathrm{S}^{-1}\right)$ & 12.7 & 11.2 & 30.2 & 138 & 275 & 235 \\
\hline Alkalinity $\left(\mu e \mathrm{q}^{-1}\right)$ & 1.3 & 18.3 & 100 & 1357 & 2749 & 1900 \\
\hline $\mathrm{pH}$ & $4.8-6.3$ & $5.3-6.6$ & $6.1-7.3$ & $7.8-8.6$ & 8.35 & 8.1 \\
\hline $\left.\mathrm{Ca}^{2 *}(\mathrm{mg})^{-1}\right)$ & 1.02 & 1.1 & 3.1 & 25.2 & 35.0 & 44.0 \\
\hline $\mathrm{Na}^{+}\left(\mathrm{mg} \mathrm{l}^{-1}\right)$ & 0.25 & $0.2 \hat{6}$ & 0.41 & 0.08 & 0.6 & 1.0 \\
\hline $\mathrm{Cl}^{-}\left(\mathrm{mg} \mathrm{l}^{-1}\right)$ & 0.13 & 0.10 & 0.11 & 0.20 & 1.0 & 2.9 \\
\hline $\mathrm{Al}_{\text {diss }}\left(\mu \mathrm{g} \mathrm{l}^{-1}\right)$ & 40 & $<15$ & $<15$ & $<10$ & $<10$ & - \\
\hline $\mathrm{Cd}\left(\operatorname{\mu g\mathrm {gl}^{-1})}\right.$ & 0.114 & 0.068 & 0.036 & 0.036 & 0.02 & 0.01 \\
\hline
\end{tabular}


ded in methyl methacrylate. Sections $3 \mu \mathrm{m}$ thick were stained with Giemsa, haematoxylin-eosin or periodic acid-Schiff (PAS). The numbers of hepatocellular nuclei with distinct glycogen vacuoles (occupying more than one-third of the nuclear area) were counted under the light microscope (Weibel 1979) and calculated as percentage of total number of nuclei; for each section, 400 nuclei were inspected. The number of hepatocytes with fatty degeneration was monitored semiquantitatively.

Electron microscopy. For electron microscopy, 6 individuals were taken each from SOS (July, September), GRS (September) and OPL (June). Fish were anaesthetized in 4-aminobenzoic acid ethyl ester (benzocaine; $50 \mathrm{mg} \mathrm{1}^{-1}$ ). In situ cardiac perfusion fixation was achieved through the ventricular wall using a $3.5 \mathrm{~mm}$ I.D. Tygon ${ }^{\text {rm }}$ tube (Ismatec, Switzerland) and a blunt $1.2 \mathrm{~mm}$ steel needle with a terminal opening of 0.8 to $1.0 \mathrm{~mm}$ (Microlance ${ }^{\mathrm{m}}$, Becton \& Dickinson, Dublin, Ireland). The vasculature was flushed with $4^{\circ} \mathrm{C}$ fish physiological saline $(0.9 \%)$ containing $2 \%$ polyvinylpyrrolidone (PVP; Merck, Darmstadt, FRG) and 0.5\% procaine hydrochloride (Serva, Heidelberg, FRG) for $30 \mathrm{~s}$ to remove blood cells. This was followed by $1.5 \%$ glutardialdehyde and $1.5 \%$ formaldehyde (freshly prepared from paraformaldehyde) in $0.1 \mathrm{M}$ sodium phosphate buffer ( $\mathrm{pH} 7.6)$ containing $2.5 \%$ PVP $\left(4^{\circ} \mathrm{C}\right)$. Initial perfusion rate was adjusted to 12 to $15 \mathrm{ml} \mathrm{min}^{-1}$. Livers were excised immediately after perfusion, immersed in perfusion fixative, and cut into slices of 60 to $70 \mu \mathrm{m}$ using an Oxford ${ }^{\mathrm{TM}}$ vibratome. Fixation was continued in $2.5 \%$ glutardialdehyde in $0.1 \mathrm{M}$ sodium cacodylate buffer ( $\mathrm{pH} 7.6$ ) containing 4\% PVP and $0.05 \%$ calcium chloride for $20 \mathrm{~min}$.

For visualization of peroxisomes, catalase peroxidatic activity was demonstrated using alkaline 3,3'diaminobenzidine (DAB; Le Hir et al. 1979): Tissue slices were incubated in $10 \mathrm{mM}$ Teorell-Stenhagen buffer ( $\mathrm{pH} \mathrm{10.0)}$ containing $5 \mathrm{mM} \mathrm{DAB}$ and $0.5 \% \mathrm{H}_{2} \mathrm{O}_{2}$ for $60 \mathrm{~min}$ at $37^{\circ} \mathrm{C}$ in a shaking water bath. After repeated rinsing in Teorell-Stenhagen and cacodylate buffers, tissue slices were postfixed for $1 \mathrm{~h}$ with $1 \%$ osmium ferrocyanide (Karnovsky 1971).

After triple washing in $0.1 \mathrm{M}$ cacodylate and $0.05 \mathrm{M}$ maleate buffer ( $\mathrm{pH} 5.2$ ), tissues were stained en bloc with $1 \%$ uranyl acetate in maleate buffer for $1 \mathrm{~h}$. Specimens were dehydrated in a graded series of ethanol and embedded in Spurr's medium. Ultrathin sections of 60 of $80 \mathrm{~nm}$ thickness were stained with alkaline lead citrate for $30 \mathrm{~s}$ or $1 \mathrm{~min}$ and examined in a Zeiss EM 9 or a Zeiss EM 10 electron microscope.

Semithin plastic sections of 0.5 to $0.75 \mu \mathrm{m}$ were stained with methylene blue-Azur II and used for orientation. For visualization of glycogen, semithin sections were incubated in an alkaline $1 \%$ solution of silver diamine for $1.5 \mathrm{~h}$ at $60^{\circ} \mathrm{C}$. After rinsing in distilled water, sections were mounted in Entellan and examined in a Leitz Aristoplan photomicroscope.

Statistics. Data are presented either as means in normally distributed samples or as medians with $25 \%$ and $75 \%$ percentiles in non-normally distributed samples. Differences between groups were tested by means of the Student-Newman-Keuls test (pairwise comparison) or by Kruskal-Wallis 1-way analysis on ranks in nonnormally distributed samples. Spearman rank order correlation was applied for testing relationships between 2 variables.

\section{RESULTS}

\section{Water analyses}

In winter, water $\mathrm{pH}$ of high alpine lakes is generally lower than in summer (Fig. 1). In extremely low alkalinity lakes (SOS and MPL), pH gradually decreased towards the ice-break. This may be the effect of both accumulating $\mathrm{CO}_{2}$ and acid run-off occurring as episodic events up to 2 mo prior to ice break. In SOS, MPL, and DRS, water is exclusively supplied by the run-off from the catchment area. The circumneutral lake (OPL) reached minimum pH much earlier, which may be attributed to increasing volumes of the permanent water inflow during snow melt (April to June). In

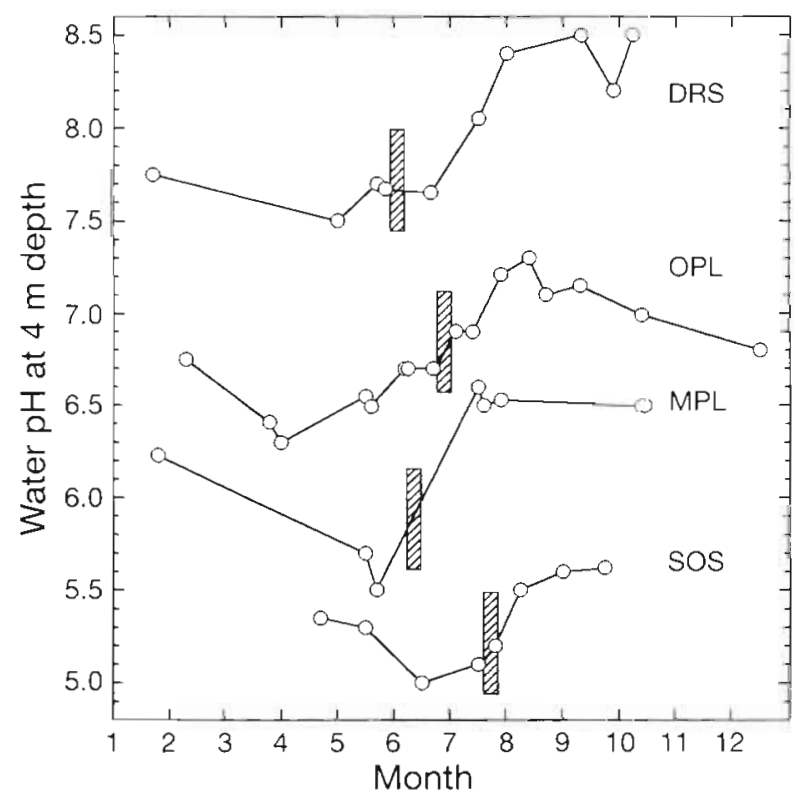

Fig. 1. Seasonal pattern of $\mathrm{pH}$ in 4 high mountain lakes of different alkalinities measured at $4 \mathrm{~m}$ depth. Columns represent the period of ice break. DRS: Drachensee; OPL: Oberer Plenderlesee; MPL: Mittlerer Plenderlesee; SOS: Schwarzsee 


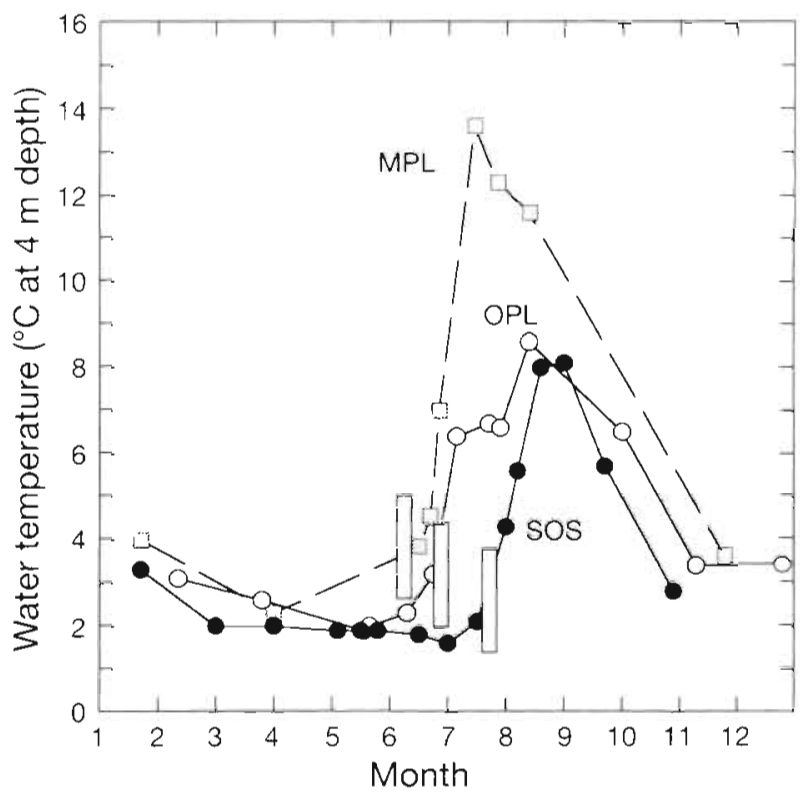

Fig. 2. Seasonal pattern of water temperature in $4 \mathrm{~m}$ depth Columns represent period of ice break. MPL: Mittlerer Plenderlesee; OPL: Oberer Plenderlesee; SOS: Schwarzsee

the well-buffered low altitude lakes (ACH and GRS), however, $\mathrm{pH}$ remained almost constant throughout the year. SOS and MPL were acidic even in summer. Whereas temperature profiles were similar in OPL, SOS and DRS, maximum temperature of MPL in summer was considerably higher (Fig. 2). Surface temperatures of $20^{\circ} \mathrm{C}$ and more were reached in low altitude lakes. During summer, however, Arctic char prefer deeper water layers with temperatures below $17^{\circ} \mathrm{C}$

Cadmium concentrations in SOS displayed seasonal fluctuations with maxima in spring (Fig. 3).

\section{Macroscopic observations}

The status of fish populations is summarized in Table 2: the dwarfed and dense population of OPL

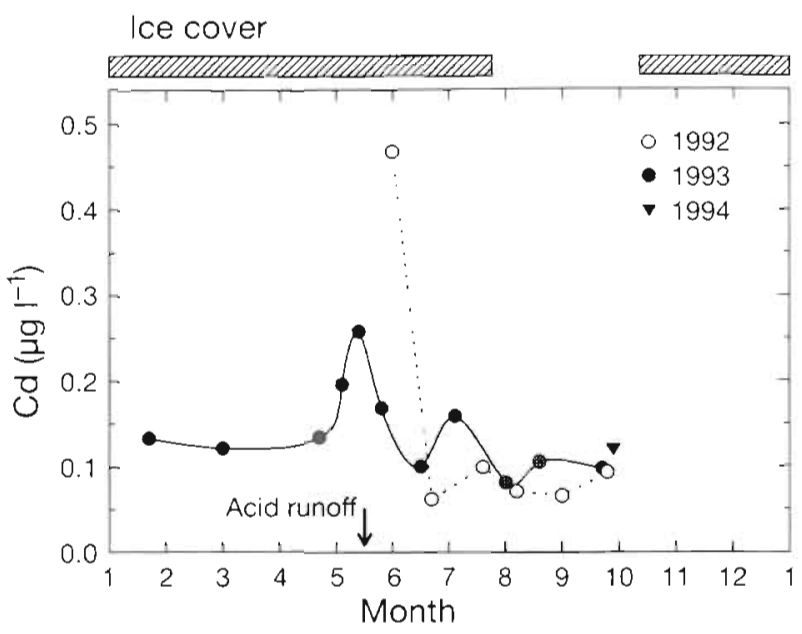

Fig. 3. Seasonal pattern of cadmium concentrations $(0.45 \mu \mathrm{m}$ filtered) in Schwarzsee. Data represent volume-weighted means

is typical of oligotrophic high mountain lakes. In acidic lakes (SOS and MPL), however, fish growth was significantly higher and condition better due to the failure of reproduction during the last few years which resulted in a decline of population densities (authors' unpubl. results). In DRS, the population density of Arctic char is controlled by piscivorous Salvelinus namaykush. In consequence, in DRS growth rate, but not condition factor, of Arctic char was higher than in OPL. Whereas condition factors of the commercially used Arctic char from $\mathrm{ACH}$ and GRS were similar to those of the acidic lakes, growth rates were higher

In winter, stomach filling rate in Arctic char from SOS is significantly lower $(p<0.05)$ than that during ice break and summer (Fig. 4), when emerging aquatic and terrestrial insects (allochthonous diet) represent the main portion of the diet (authors' unpubl. data). A similar seasonal pattern can be demonstrated with the liver-somatic index (relative liver weight in \% body weight) for both sexes being significantly increased $(p<0.05)$ during early summer.

Table 2. Salvelinus alpinus. Morphometric characterization of fish used for histological analysis of the lıver. SOS: Schwarzsee; MPL: Mittlerer Plenderlesee; OPL: Oberer Plenderlesee; DRS: Drachensee; ACH: Achensee; GRS: Grundisee

\begin{tabular}{|c|c|c|c|c|c|c|}
\hline & SOS & MPL & OPL & DRS & $\mathrm{ACH}$ & GRS \\
\hline Body length $\left(L_{i} \mathrm{~cm}\right)$ & $23.7-2.1$ & $25.3-3.1$ & $13.8-1.8$ & $21.1-1.7$ & $27.2-7.6$ & $30.6-3.2$ \\
\hline Body weight $(W ; g)$ & $107.5-28.2$ & $132.9-49.2$ & $18.0-7.3$ & $62.9-14.5$ & $210.0-167.0$ & $249.7-65.9$ \\
\hline Condition factor $\left(100 \times W / L^{3}\right)$ & $0.81-0.1$ & $0.82-0.09$ & $0.68-0.06$ & $0.67-0.07$ & $0.81-0.09$ & $0.85-0.06$ \\
\hline Age $(y r)$ & $5-16$ & $4-15$ & $3-9$ & $4-8$ & $4-9$ & $4-6$ \\
\hline Number of fish (n) & 87 & 16 & 75 & 16 & 41 & 19 \\
\hline Reproduction & No & No & Yes & Yes & Yes & Yes \\
\hline
\end{tabular}




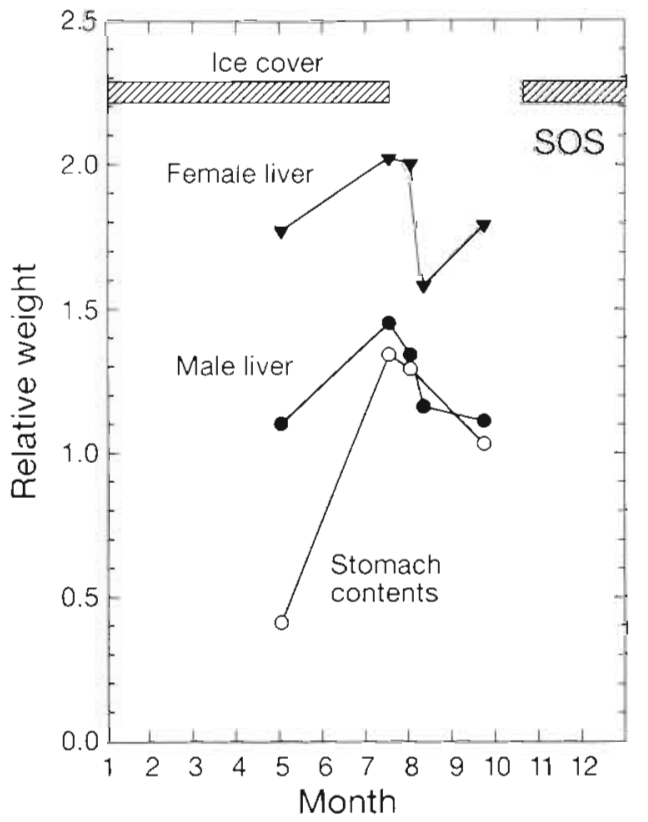

Fig. 4. Salvelinus alpinus. Relative weights of stomach contents and livers of male and female Arctic char from Schwarzsee. Data recorded from winter fish are significantly different from those in fish caught during and immediately after ice break. Data presented as means

\section{Light microscopy}

Glycogen accumulation in hepatocellular nuclei as indicated by positive PAS reaction was a characteristic feature of the liver of Arctic char in the 2 acidic lakes (SOS and MPL; Figs. $5 \& 6$ ). In SOS, the relative

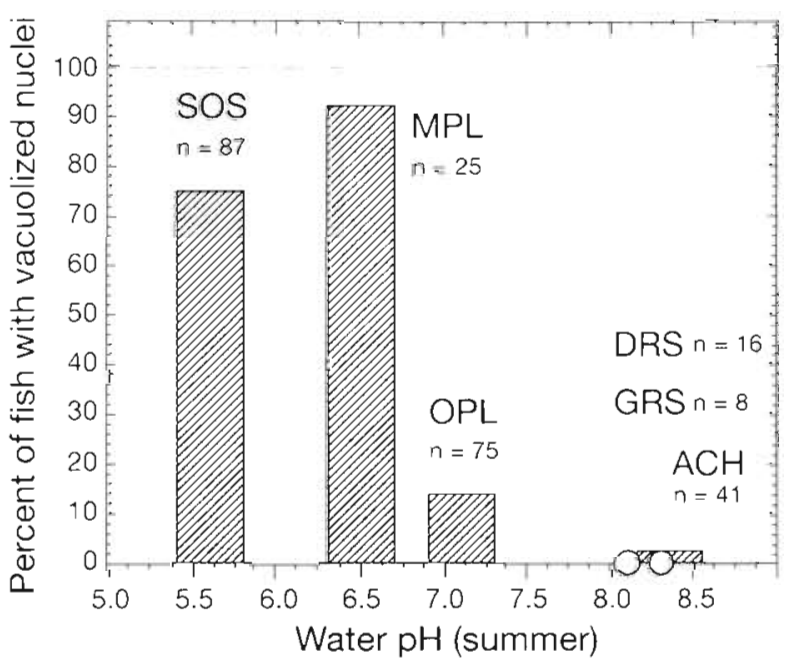

Fig. 6. Salvelinus alpinus. Percentage of Arctic char with vacuolized hepatocyte nuclei in 6 alpine lakes of different water $\mathrm{pH}$ (for means of water $\mathrm{pH}$ in summer, see Table 1 ). SOS: Schwarzsee; MPL: Mittlerer Plenderlesee; OPL: Oberer Plenderlesee; DRS: Drachensee; ACH: Achensee; GRS: Grundlsee

number of fish with nuclear vacuolization rates of more than $1 \%$ was almost constant throughout the year (58 to $87 \%$ ) and did not correlate with age or sex. The degree of vacuolization, however, showed a distinct seasonal pattern (Fig. 7): Whereas occurrence was low during autumn and winter, there was a significant peak $(p<0.05)$ immediately after the ice break. In fish of the circumneutral OPL, however, only a few specimens ( $14 \%$ of the total population) displayed a relatively small number of vacuolized nuclei (<4\%; Fig. 6). This alteration was absent in Arctic char from an alkaline high mountain lake (DRS) and 2 alkaline lakes at low altitudes (except in 1 out of 41 specimens from $\mathrm{ACH}$ )

\section{Electron microscopy}

The present communication is focused on variations in ultrastructure and glycogen storage of hepatocyte nuclei, since only these could be unambiguously correlated to ecological parameters, whereas differences in cytoplasmic appearance could also be attributed to different sex and age. A semiquantitative comparison of differences in the ultrastructural appearance of Arctic char hepatocytes be-
Fig. 5. Salvelinus alpinus. Hepatocyte nuclei with PAS-positive (glycogen) vacuoles (arrowheads) of Arctic char from Schwarzsee; $\times 400$ 


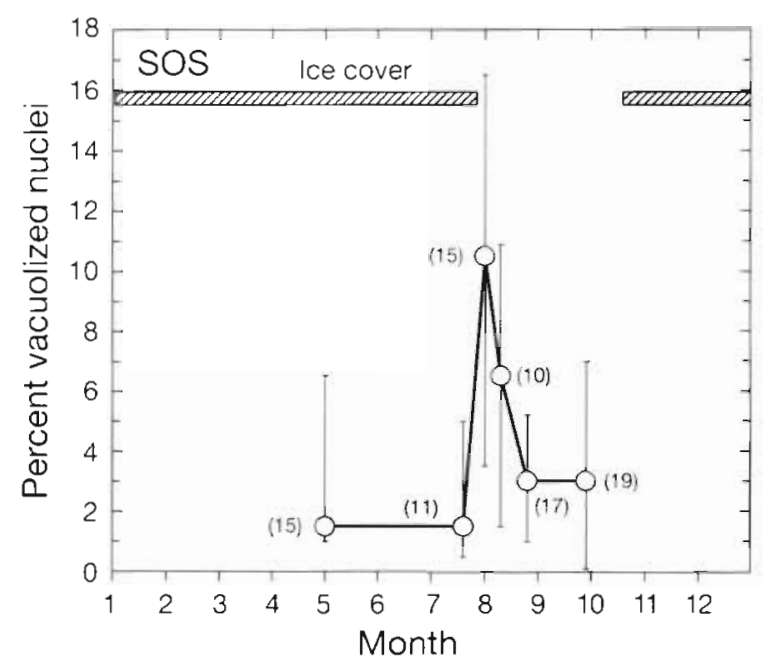

Fig. 7. Salvelinus alpinus. Seasonal pattern of vacuolization rate of hepatocellular nuclei in Arctic char from Schwarzsee. Medians, 25 and $75 \%$ percentiles as well as number of fish investigated (parentheses) are given

tween fish from Grundlsee (GRS), Schwarzsee (SOS) and Oberer Plenderlesee (OPL) is given in Table 3.

Arctic char from Grundlsee (GRS). Arctic char from GRS displayed little sexual dimorphism. Parenchymal heterogeneity was low, and livers were free of necrotic areas. Hepatocytes were polygonal and showed a distinct cytoplasmic compartmentation (cf. Braumbeck et al. 1987) into an organelle-rich perinuclear region containing rough endoplasmic reticulum (RER), mitochondria and peroxisomes and a peripheral zone enriched in storage products such as glycogen and lipid (Fig. 8).

Centrally located, the single nucleus was almost spherical with a smooth outline. Each nucleus contained a slightly eccentric nucleolus with the pars fibrosa arranged in discrete patches of slightly higher electron density than the pars granulosa. Both nuclear and nucleolar diameters as well as the degree of separation of nucleolar pars fibrosa and pars granulosa were similar in males and females. Heterochromatin was sparse and restricted to the nuclear periphery and to very few randomly distributed patches of different size (Fig, 8). Binucleated hepatocytes and nuclear lipid inclusions were extremely rare.

Peripheral storage areas were occupied by small fields of glycogen rosettes (Fig. 8), which were occasionally associated with irregular profiles of smooth endoplasmic reticulum (SER), and lipid droplets. Glycogen contents were slightly lower in females versus males. The amount of lipid varied especially between individual male fish.

Arctic char from Schwarzsee (SOS). If compared to GRS char, parenchymal heterogeneity was conspicuously higher with respect to variations between both different individuals and within one specimen. Whereas cytoplasmic compartmentation was at least partly preserved in some SOS individuals (Fig. 9), hepatocytes of other SOS char completely lacked any separation of organelle-containing cytoplasm and storage areas. Independent of sex, about $50 \%$ of the SOS fish displayed extracellular spaces distended to variable degrees (Fig. 9).

Whereas light microscopically detectable PAS-positive areas within nuclei (Fig. 5) could be identified even at low electron microscopic magnifications as dense fields of monoparticulate glycogen (Fig. 9), the overall amount of cytoplasmic glycogen was slightly lower than in GRS fish (Fig. 8). Development of nuclear glycogen deposits from cytoplasmic invaginations into the nucleoplasm could be excluded, since glycogen areas were never enclosed within duplicate membranes (Figs 8 to 10). Primarily due to glycogen reduction, but also due to comparatively low amounts of endoplasmic reticulum, 
Fig. 8. Salvelinus alpinus. Hepatocytes of Arctic char from Grundlsee were polygonal and showed a distinct cytoplasmic compartmentation into an organelle-rich perinuclear region containing rough endoplasmic reticulum (RER), mitochondria and peroxisomes and a peripheral zone enriched in storage products such as glycogen and lipid. In the biliary area facing bile canaliculi (bc), the regular stacking of RER cisternae was regularly interrupted by Golgi fields and lysosomes. he: hepatocellular nucleus. Female; $\times 5900$

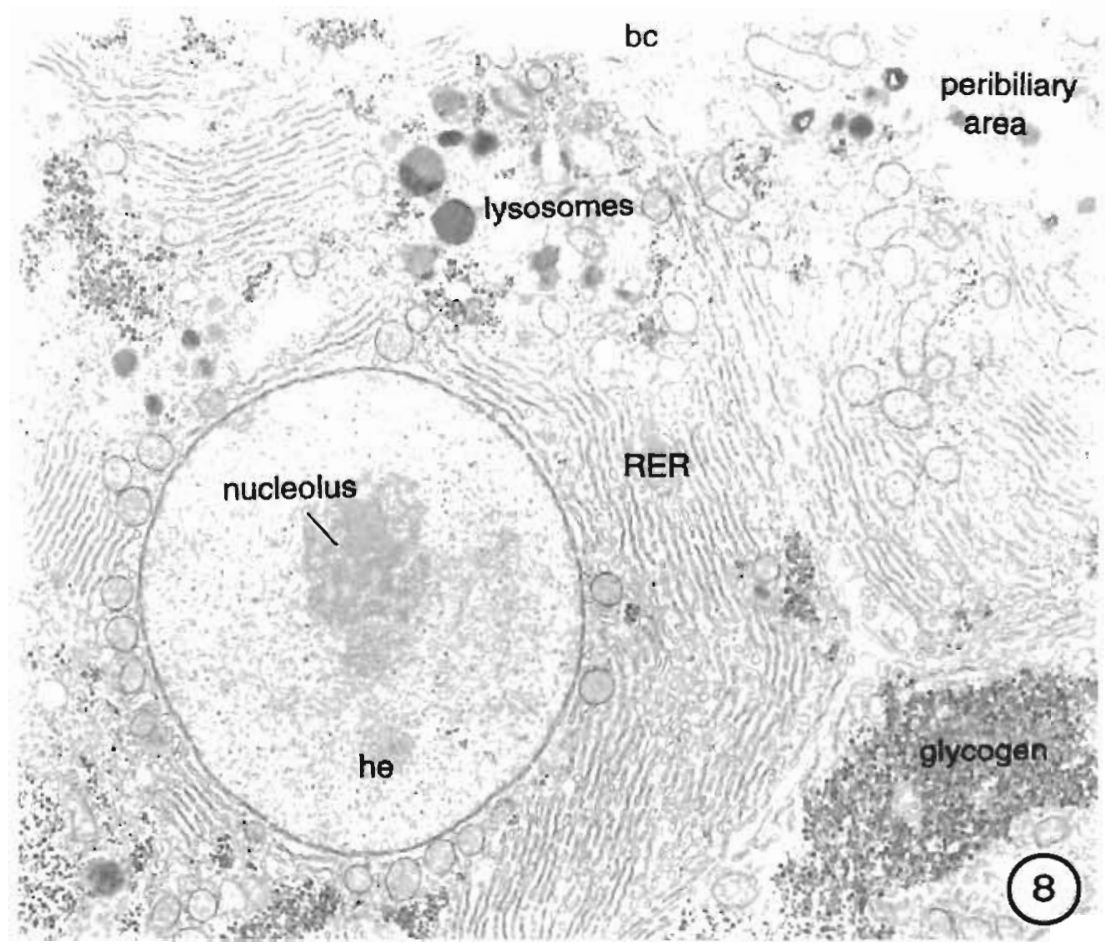

hepatocellular size was conspicuously reduced in SOS char.

Glycogen deposits in nuclei of SOS char mannly consisted of monoparticulate $\beta$-particles, the mean size of which (ca $40 \mathrm{~nm}$ ) did not differ from that of single components of cytoplasmic $\alpha$-glycogen rosettes (30 to $50 \mathrm{~nm}$; Figs. $10 \& 11$ ). Due to their increased electron density, glycogen particles could easily be distinguished from granular components of heterochromatin (Fig. 11). In addition to fields of $\alpha$-glycogen, nuclei of SOS char also displayed closely defined areas with fine granular inclusions with a mean diameter of 20 to $25 \mathrm{~nm}$ (Figs. 10 \& 12) resembling interchromatın granules (Bouteille et al. 1974). Neither glycogen nor fine granular deposits showed any preferential localization within nuclei. Whereas nuclear size did not differ from GRS char, the number of binucleate cells was greater compared to SOS char.

Depending on the plane of section, hepatocellular nucleoli of 5 out of 6 SOS char sampled in July displayed a zebra- or honeycomb-like arrangement of nucleolar components (Figs. $13 \& 14$ ). The diameter of the spherical electron-lucent areas in crosssections averaged $100 \mathrm{~nm}$ and regularly displayed a 50 to $55 \mathrm{~nm}$ filamentous core of medium electron density most likely representing chromatın clumps (Fig. 13, present study; cf. Bernhard \& Granboulan 1968). In addition, in SOS char caught in July there was an elevated number of hepatocytes with multiple nucleoli.
Glycogen depletion in SOS char was accompanied by a decline in hepatocellular lupid deposits (compare Figs, 8 \& 9). Increased levels of lipidolysis was also indicated by a considerably more heterogeneous outline of lipid droplets (Fig. 9) and a most intimate assoclation between highly elongate mitochondria and lipid droplets.

Arctic char sampled in Oberer Plenderlesee (OPL). With respect to hepatocellular ultrastructure, Arctic char from the curcumneutral Oberer Plenderlesee (OPL) took an intermediate position between GRS and SOS fish. Parenchymal heterogeneity was as low as in GRS char; cytoplasmic compartmentation into organellecontaining areas and glycogen fields, however, was not evident due to almost complete glycogen exhaustron. Except for a slight distension of the nuclear envelopes and mild glycogen storage within the nucleus of one individual, nucleı as well as nucleoli were free of pathological symptoms

\section{DISCUSSION}

The present study clearly documents profound multiple modifications of structure and ultrastructure in hepatocyte nuclei of Arctic char from acidic lakes. Without doubt, the most conspicuous and unusual alteration is the accumulation of glycogen in the nucleoplasm. Since nuclear glycogen was consistently monoparticulate and never enclosed within separate 


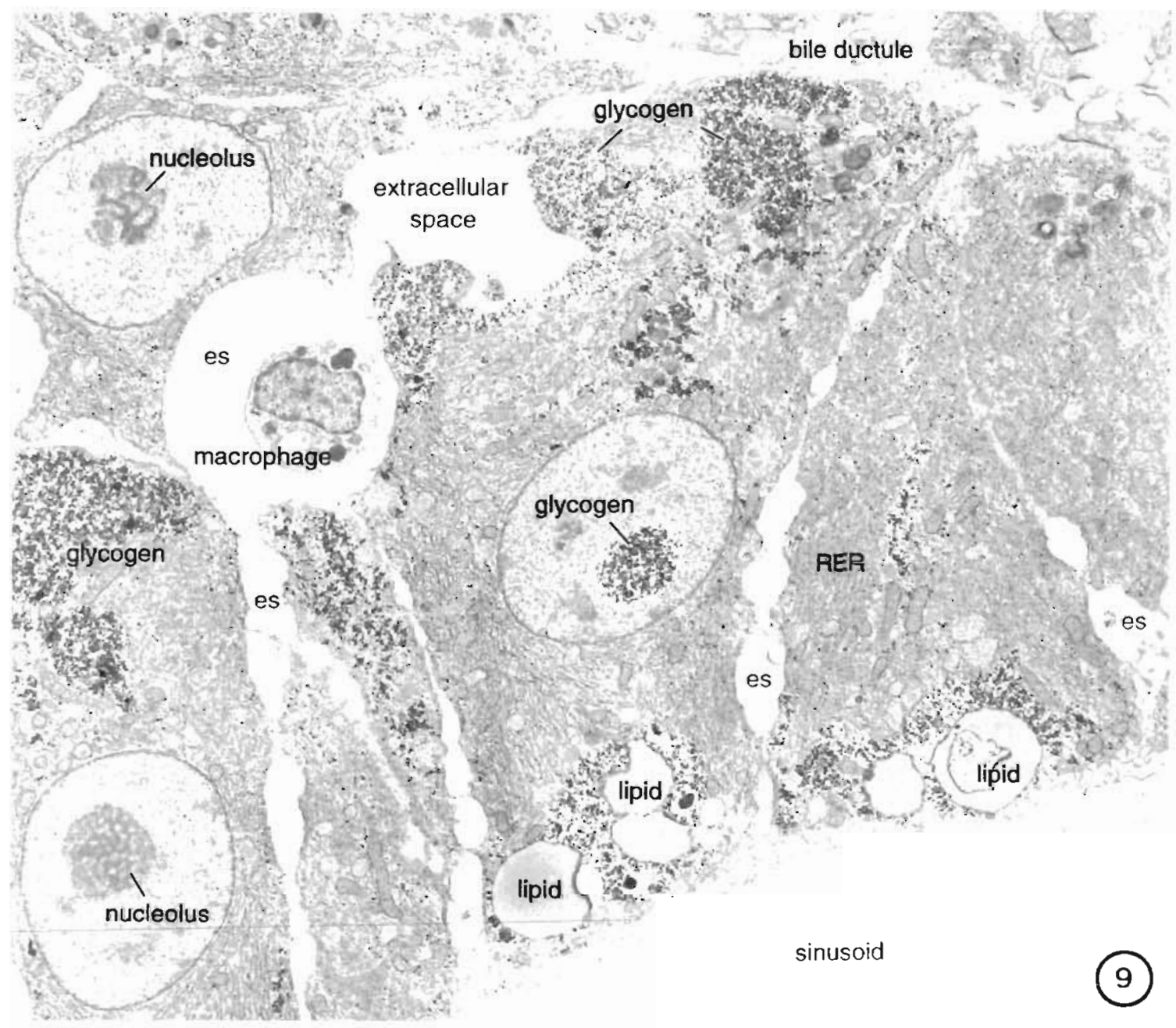

Fig 9 Salvelunus alpinus In Arctıc char sampled in Schwarzsee in July, hepatocytes displayed conspicuous glycogen deposits as well as nucleol. with a typical honeycomb-like appearance The cytoplasmic compartmentation into an organelle-containing areas and peripheral zones with storage products (glycogen, lipid) was inferior to that of Crundlsee char (cf. Fig. 8). The overall amount of cisternae of the rough endoplasmuc retıculum (RER) was drastically reduced, if compared to Grundlsee char. Cytoplasmic glycogen depletion in Schwarzsee Arctic char was accompanied by a decline in hepatocellular lipid deposits. Extracellular spaces (es) between hepatocytes were severely distended and frequently contained invading macrophages. Female $\times 3800$

membranes, the possible origin from cytoplasmic indentations, including glycogen rosettes ( $\alpha$-glycogen), into nuclei may be excluded. In contrast, Thiyagarajah \& Grizzle (1986) described $\alpha$-glycogen in addition to predominant $\beta$-particles in hepatocyte nuclel of RIvulus marmoratus. Since in $R$. marmoratus glycogen has also been found within nuclear pores, Thiyagarajah \& Grizzle concluded that at least parts of glycogen might be imported into nuclel from the cytoplasm. As shown by Karasakı (1971), massive accumulation of glycogen can rapidly occur in nuclei of human hepatoma cells without the occurrence of similar deposits in the cytoplasm at periods of active DNA synthesis, provided the nuclear envelope is intact. In fact, dunng the period of ice break, the metabolism of Arctic char from high mountain lakes is highly activated, which most likely also includes accelerated DNA synthesis. After a period of 9 mo with reduced feeding, ice break dramatically changes light intensity, temperature and food supply. However, nuclear vacuolization has also been observed in winter after spawning, when growth and metabolism are generally reduced. Moreover, the Arctic char population in OPL is exposed to identical seasonal changes without displaying the distinct pattern of nuclear vacuoluzation typical of SOS and MPL char.

On the other hand, the sudden rise in food consumptıon (approximately 5 -fold increased relative stomach contents obtained for OPL fish; authors' unpubl. data) may result in an additional burden (due to catch of prey, active food uptake, enzyme production, etc.) for the fish from acıdic lakes. Distinct ultrastructural changes of hepatocytes could also be shown for the 


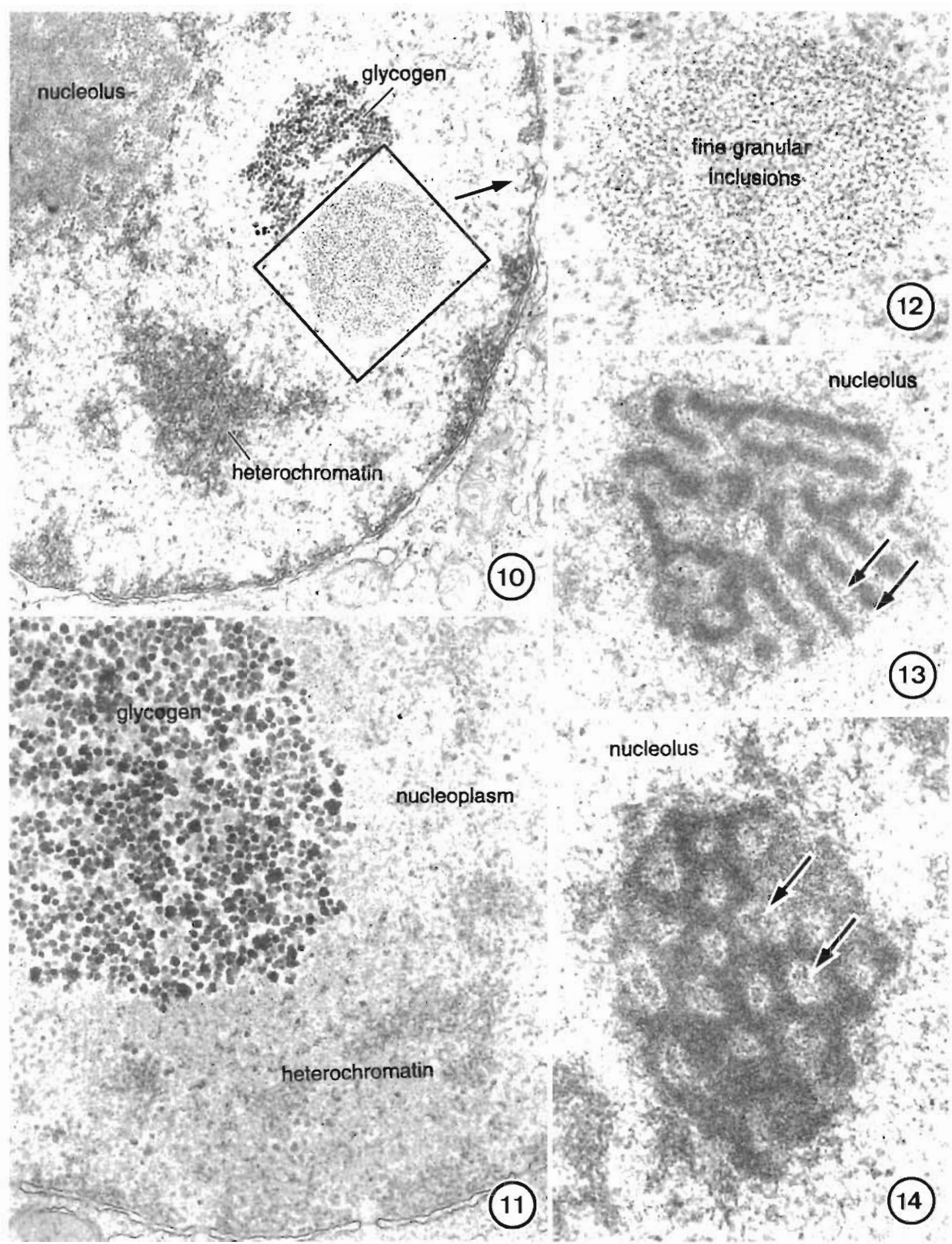

Figs. 10 to 14. Salvelinus alpinus Ultrastructural alterations un nuclei of Arctic char sampled in Schwarzsee comprised deposition of monoparticulate ( $\beta$-)glycogen withun the nucleoplasm (average diameter $40 \mathrm{~nm}$. Figs. 10 \& 11) as well as formation of fine granular deposits with a mean diameter of 15 to $20 \mathrm{~nm}$ (Fig 10, box; Fig 12). Depending on the plane of section, nucleoll showed a zebra- (Fig. 13) or honeycomb-like (Fig. 14) arrangement of nucleolar components with electron-lucent areas of $100 \mathrm{~nm}$ regularly displaying a 50 to $55 \mathrm{~nm}$ filament-like core of medium electron density (Figs 13 \& 14; arrows) between areas of ıncreased electron density Males sampled un July (Figs 11 to 14) or September (Fig. 10). Fig 10, ×23800; Fig. 11, × 33300; Fig. 12, $\times 45000$; Fig 13, × 25700, Fig. 14, × 30800 
resumption of active nutrition in early spring in field populations of golden ide (Leuciscus idus melanotus; Segner \& Braunbeck 1990).

In the acidic lakes only (SOS, MPL), the majority of fish displayed distinct nuclear glycogen accumulation. In Arctic char of the circumneutral lake (OPL), however, nuclear alterations have only been seen occasionally and were even absent (with the exception of 1 individuall in fish from alkaline waters including those from a high altitude lake (DRS). Since environmental conditions except alkalinity-related parameters such as $\mathrm{pH}$ and calcium concentration of the water and, as a consequence, the increased accumulation of lead and cadmium in fish organs (Köck et al. 1995) are similar in the 4 high altitude lakes, one of these parameters or probably a combination of parameters may be made responsible for nuclear alterations. Aluminum, however, can be excluded as the primary inducer, since it reaches only slightly toxic concentrations in SOS, but not in MPL (Table 1). Furthermore, annual cycles of $\mathrm{pH}$ or cadmium concentration in SOS did not directly correlate with the seasonal pattern of the frequency of vacuolized nuclei.

Besides nuclear glycogen accumulation, livers of Arctic char from SOS and partly from MPL displayed a multitude of further pathological effects, which might at least partly be attributed to the acidic conditions of the lakes. The extraordinarily high accumulation of cadmium and lead in kidneys and livers of Arctic char (Köck et al. 1995), as well as the highly disturbed reproduction of these fishes, support this assumption. Furthermore, in SOS char muscle, concentrations of some organic pesticides ( $p$ 'p-DDE, PCBs) are higher than in those of comparable remote European lakes (J. O. Grimalt pers. comm.).

Since hepatocytes are involved in exogenous vitellogenesis (Van Bohemen et al. 1981, 1982), impaired liver metabolism may well account for delayed or reduced spawning of fish in acidic lakes (Beamish et al. 1975, McCormik et al. 1989). In fact, Arctic char of OPL reproduce in October; the population of SOS, however, does not spawn before December. During the past few years, in fish populations from SOS and MPL, the absence of young individuals indicated complete failure of reproduction (authors' unpubl. results). While population size declined, nutritional status and growth of remaining fish improved. Probably due to reduced intraspecific competition, the maximum age of char is high (up to $16 \mathrm{yr}$ ). This, in turn, resulted in the high incidence of pathological livers predominantly seen in specimens older than 10 yr. Nuclear glycogen, however, was independent of age and also common in 5 yr ald fish.

In natural or cultured populations of fish, glycogen accumulation in hepatocyte nuclei is generally un- known except in studies on Micropterus salmoides (Hibiya 1982) and Rivulus marmoratus (Thiyagarajah \& Grizzle 1985, 1986). However, none of these authors provided a useful interpretation of this phenomenon. In contrast, in mammalian pathology, nuclear glycogen accumulation has been described in association with a multitude of diseases including primary or secondary diabetes mellitus, type I glycogen storage disease, Wilson's, Grave's and Hodgkin's diseases, Lupus erythematosus, stomach carcinoma, hepatoma, infective hepatitis, total lipodystrophy, as well as Gilbert's and Rotor syndrome (for reviews, see Arias et al. 1988 as well as Phillips et al. 1987). In addition, with markedly different ultrastructural appearance, hepatocellular nuclear glycogenosis was found after administration of drugs such as amidiodarone, cimetidine, cyanamid or methotrexate.

In mammalian liver, however, nuclear glycogen storage caused by metabolic diseases is usually associated with other specific pathological conditions such as steatosis or cirrhosis (Petersen \& Christoffersen 1979, Philips at al. 1987), which have not been observed in Arctic char. In fact, other symptoms of liver damage in Arctic char from SOS and MPL did not correlate with nuclear glycogen formation. As a consequence, nuclear vacuolization may be supposed to be an indication of an exceptional metabolic status induced by the specific water chemistry of acidic soft water lakes at high altitudes. Although this alteration might be pathological, there is no convincing evidence for a specific metabolic disease such as those described for mammals and man.

Acknowledgements. This investigation was supported by the 'Fonds zur Förderung der wissenschaftlichen Forschung in Osterreich', project no. P08970-BIO. We thank Gun Sonntag and Gisela Adam for excellent technical assistance, H. Cia and S. Pechlaner, the communities of Sölden and Innsbruck, as well as the 'Osterreichischen Bundesforste' for providing fishing permits. The study was carried out in cooperation with the project of the European Commissions AL:PE-2, no. EV5VCT92-0205.

\section{LITERATURE CITED}

Arias IM., Jakoby WB, Popper H, Schachter D, Shafritz DA (1988) The liver. Biology and pathobiology, 2nd edn. Raven Press, New York

Backes CA, Tipping E (1987) Aluminium complexation by an aquatic humic fraction under acidic conditions. Water Res $21: 211-216$

Baker JP, Chofield CL (1982) Aluminum toxicity to fish in acldic waters. Water Air Soil Pollut 18:289-310

Beamish RJ, Lockhart WL, Van Loon JC, Harvey HH (1975) Long-term acidification of a lake and resulting effects on tishes. Ambio 4:98-102

Bernhard W, Granboulan N (1968) Electron microscopy of the 
nucleolus in vertebrate cells. In: Dalton AJ, Haguenau F (eds) The nucleus. Academic Press, New York, p 81-149 Bouteille M, Laval M. Dupuy-Coin AM (1974) Localization of nuclear functions as revealed by ultrastructural autoradiography and cytochemistry. In: Busch $\mathrm{H}$ (ed) The cell nucleus. Academic Press, New York, p 5-71

Braunbeck T (1994) Detection of environmentally relevant pesticide concentrations using cytological parameters: pesticide specificity in the reaction of rambow trout liver? In: Müller R, Lloyd R (eds) Sublethal and chronic effects of pollutants on freshwater fish. Blackwell Scientific, Oxford, p 15-29

Braunbeck T, Gorgas K, Storch V, Völkl A (1987) Ultrastructure of hepatocytes in golden ide (Leuciscus idus melanotus L.; Cyprinidae: Teleostei) during thermal adaptation. Anat Embryol 175:303-313

Bulger AJ, Leino L, Cosby BJ, Hendriksen A (1993) Brown trout (Salmo trutta) and chemistry from the Norwegian Thousand Lake survey: statistical analysis. Can J Fish Aquat Sci 50:575-585

Chevalier G, Gauthier L, Moreau G (1985) Histopathological and electron microscopic studies of gills of brook trout, Salvelinus alpinus, from acidified lakes. Can J Zool 63: 2062-2070

Daye PG, Garside ET (1979) Development and survival of embryos and alevins of the Atlantic salmon, Salmo salar L., continuously exposed to acidic levels of $\mathrm{pH}$, from fertilization. Can J Zool 57:1713-1718

Fischer-Scherl T, Hoffmann RW (1988) Gill morphology of native brown trout Salmo truttaf. fario experiencing acute and chronic acidification of a brook in Bavaria, FRG. Dis Aquat Org 4:43-51

Fromm PO (1980) A review of some physiological and toxicological responses of freshwater fish to acid stress. Environ Biol Fish 5:79-93

Harvey HH, Pierce RC, Dillon PJ, Kramer JR, Whelpdale DW (1981) Acidification in the Canadian aquatic environment: scientific criteria for assessing the effects of acid deposition on aquatic ecosystems. National Research Council of Canada. Associate Committee on Scientific Criteria of Environmental Quality. NRCC Publ No 18475

Hendriksen A, Lien L, Rosseland BO, Traaen TS, Sevaldrud IS (1989) Lake acidification in Norway: recent and predicted fish status. Ambio 18:314-321

Hibiya $T$ (1982) An atlas of fish histology: normal and pathological features. Kondansha Press, Tokyo

Hoenicke R, Stapanian MA, Arent LJ, Metcalfe RC (1991) Consequence of pH measurement errors. Freshwater Biol 25:261-278

Hutchinson NJ, Holtze KE, Munro JR, Pawson TW (1987) Lethal responses o salmonid early life stages to $\mathrm{H}^{+}$and Al in dilute waters. Ann Soc R Zool Belg 117 (Suppl 1): 201-217

Hutchinson NJ, Sprague JB (1989) Lethality of trace metal mixtures to American flagfish in neutralized acid water. Arch Environ Contam Toxicol 18:249-254

Karasaki S (1971) Cytoplasmic and nuclear glycogen synthesis in Novikoff ascites hepatoma cells. J Ultrastr Res 35: 181-196

Karlsson-Norrgren L, Bjorklund I, Ljungberg O, Runn P (1986a) Acid water and aluminium exposure: experimentally induced gill lesions in brown trout, Salmo trutta L. J Fish Dis 9:11-26

Karlsson-Norrgren L, Dickson W, Ljungberg O, Runn P (1986b) Acid water and aluminium exposure: gill lesions and aluminium accumulation in farmed brown trout, Salmo trutta L. J Fish Dis 9:1-10
Karnovsky MJ (1971) Use of ferrocyanide-reduced osmium tetroxide in electron microscopy. J Cell Biol (Abstract) 51: $146 \mathrm{~A}$

Köck G, Hofer R, Wögrath S (1995) Accumulation of trace metals (Cd, Pb, Cu, Zn) in Arctic char (Salvelinus alpinus) from oligotrophic Alpine lakes: relation to alkalinity. Can J Fish Aquat ScI 52:2367-2376

Le Hir M, Herzog V, Fahimi HD (1979) Cytochemical detection of catalase with 3,3'-diaminobenzidine. A quantitative reinvestigation of the optimal assay conditions. Histochem 64:51-66

Leino RL, McCormick JH (1984) Morphological and morphometric changes in chloride cells of the gills of Pimephales promelas after chronic exposure to acid water. Cell Tissue Res 236:121-128

Leino RL, McCormick JH, Jensen KM (1987a) Changes in gill histology of fathead minnow and yellow perch transferred to soft water or acidified water with particular reference to chloride cells. Cell Tissue Res 250:389-399

Leino RL, Wilkinson P, Anderson JG (1987b) Histopathological changes in the gills of the pearl dace, Semotilus margarita, and fathead minnows, Pimephales promelas, from experimentally acidified Canadian lakes. Can J Fish Aquat Sci 44 (Suppl 1):126-134

Mason J (1989) The causes and consequences of surface water acidification. In: Morris R, Taylor EW, Brown DJA, Brown JA (eds) Aquatic toxicity and aquatic animals. Society for Experimental Biology Seminar Series, Vol 34 Cambridge Univ Press, Cambridge, p 1-12

McCormick JH, Stokes GN, Hermanutz RO (1989) Oocyte atresia and reproductive success in fathead minnows (Pimephales promelas) exposed to acidified hard water environments. Arch Environ Contam Toxicol 18:207-214

McDonald DG (1983) The effects of $\mathrm{H}^{+}$upon the gills of freshwater fish. Can J Zool 61:691-703

McDonald DG, Wood CM (1993) Branchial mechanisms of acclimation to metals in freshwater fish. In: Rankin JC, Jensen FB (eds) Fish ecophysiology. Fish and Fisheries Series, Vol 9. Chapman \& Hall, London, p 297-321

Petersen $P$, Christoffersen P (1.979) Ultrastructure of lipogranulomas in fatty liver. Acta Pathol Microbiol Immunol Scand 87:45-49

Peute J, Huiskamp R, Van Oordt PGWJ (1985) Quantitative analysis of estradiol $17 \beta$-induced changes in the ultrastructure of the liver of the male zebrafish, Brachydanio rerio. Cell Tissue Res 242:377-382

Phillips MJ, Poucell S, Patterson J, Valencia P (1987) The liver-an atlas and text of ultrastructural pathology. Raven Press, New York

Psenner R (1994) Environmental impacts on freshwaters: acidification as a global problem. Sci Total Environ 143: $53-61$

Reader JP, Depsey CH (1989) Episodic changes in water quality and their effects on fish. In: Morris R, Taylor EW, Brown DJA, Brown JA (eds) Aquatic toxicity and aquatic animals. Society for Experimental Biology Seminar Series 34, Vol 34. Cambridge Univ Press, Cambridge, p 67-84

Sayer MDJ, Reader JP, Dalziel TRK (1993) Freshwater acidification: effects on the early life stages of fish. Rev Fish Biol Fisheries 3:95-132

Segner H, Braunbeck T (1988) Hepatocellular adaptation to extreme nutritional conditions in ide, Leuciscus idus melanotus L. (Cyprinidae). A morphofunctional analysis. Fish Physiol Biochem 5:79-97

Segner H, Braunbeck T (1990) Adaptive changes of liver composition and structure in golden ide during winter acclimatization. J Exp Zool 255:171-185 
Segner H. Linnenbach M, Marthaler R (1987) Towards a use of epidermal mucous cells in the field assessment of acid stress in fish. J Appl Ichthyol 3:187-190

Segner H, Pechlaner R (1987) Untersuchungen zur Leberkondition von Seesaiblingen, Salvelinus alpinus, aus zwei hochalpinen Seen Österreichs. Verh Dtsch Zool Ges 80: $298-299$

Thlyagarajah A, Grizzle JM (1985) Pathology of diethyl nitrosamine toxicity in the fish Rivulus marmoratus. J Environ Pathol Toxicol Oncol 6:219-232

Thiyagarajah A, Grizzle JM (1986) Nuclear glycogen and Iipid in hepatocytes of a fish. Rivulus ocellatus marmoratus. Can J Zool 64:2868-2870

Van Bohemen CG, Lambert JGD, Peute, J (1981) Annual changes in plasma and liver in relation to vitellogenesis in the female rainbow trout, Salmo gairdneri. Gen Comp

Responsible Subject Editor: C. B. Schreck, Corvallis, Oregon, USA

\section{Endocrin 44:94-107}

Van Bohemen CG, Lambert JGD, Goos HJT, Van Oordt PGWJ (1982) Estrogen and estradiol participation during exogeneous vitellogenesis in the temale rainbow trout, Salmo gaırdneri. Gen Comp Endocrin 46:81-92

Weibel ER (1979) Stereological methods for biological morphometry, Vol I. Academic Press, New York, London

Wendelaar-Bonga SE, Van der Meij JCA, Flik G (1986) Response of PAS-positive cells of the pituitary pars intermedia in the teleost Carassius auratus to acid water. Cell Tissue Res 243:609-617

Wood CM (1989) The physiological problems of fish in acid waters. In: Morris R, Taylor EW, Brown DJA, Brown JA (eds) Aquatic toxicity and aquatic animals. Society for Experimental Biology Seminar Series, Vol 34. Cambridge Univ Press, Cambridge, p 67-84

Manuscript first received: September 1, 1995

Revised version accepted: September 27, 1996 